\title{
Why do conditional cash transfer programmes fail to target the poor? The case of urban areas in Mexico
}

\author{
Pierre Levasseur
}

\begin{abstract}
Given the limited financing capacity of developing countries, conditional cash transfer (CCT) programmes are an affordable means of providing a social safety net to vulnerable households. However, compliance with conditionalities may limit participation and increase dropouts, particularly when compliance-related constraints are high and cash incentives are relatively low. This empirical analysis determines how cash transfer amounts affect the probability that participating households will remain in a programme or drop out, looking at the case of Mexico, a developing country that has gradually expanded its CCT programme from rural to urban areas. Using longitudinal household surveys, this study finds that the poorest households are most likely to drop out of the programme. Interestingly, the level of cash transfers increases this probability for the poorest participants compared to the richest ones. It is concluded that the programme does not successfully retain the poorest households in the programme, because the cash incentives are too low in urban settings.
\end{abstract}

\section{Keywords}

Income, households, poverty mitigation, economic development, rural areas, urban areas, programmes of action, programme evaluation, case studies, Mexico

\section{JEL classification}

\author{
O15, I32, H23
}

Author

Pierre Levasseur is an associate researcher at the Sciences for Action and Development - Activities, Products, Territories (SAD-APT) unit of the French National Research Institute for Agriculture, Food and Environment (INRAE). Email: pierre.levasseur@inrae.fr. 


\section{Introduction}

In developing countries, which are often over-indebted, budgetary and fiscal constraints limit the implementation of social protection systems. Many emerging countries such as Mexico have therefore opted for an alternative arrangement: conditional cash transfer (CCT) programmes. Since these programmes only target the poorest households, their cost is relatively low. The principle is simple: in exchange for cash allowances (or non-monetary benefits), participants agree to meet certain conditions (called conditionalities), with the overall aim of increasing public service demand (i.e. schools and health centres). Cash transfers are said to be "conditional" because participants who do not meet the conditionalities are excluded from the programme and stop receiving payments. The cash incentives have two main functions: (i) to encourage eligible households to take part in the programme; and (ii) to offset constraints related to the uptake of public services, such as direct costs (for example for enrolment fees, uniforms, equipment, consultations, transportation, medicines, injections) and indirect costs (including opportunity cost, loss of time). People living in poverty are particularly vulnerable to these constraints. Evidently, other factors limit poor populations' demand for public services, such as a failure to prioritize health and education. This is theoretically attributable to limited nutritional and health knowledge, and to time inconsistency (a preference for immediate gratification over an uncertain future investment in human capital, (Banerjee and Duflo, 2011)).

The Mexican CCT programme, which was first called Progresa, then Oportunidades, and is now known as Prospera, is one of the most ambitious and successful in the world (Fiszbein and others, 2009). Initially, the purpose of the programme was to eradicate hunger and extreme poverty through action on education, nutritional deficiencies and infectious diseases. Since it was established in 1997 as part of a randomized controlled trial of a few marginalized rural areas, the programme has proved to have a positive impact on human capital indicators. In view of its conclusive results, the government extended the project to all marginalized rural areas between 1998 and 2000, and then to small urban areas in 2001 and to Mexico's major cities in 2002. Since 2007, poor households from all marginalized communities of the country (both rural and urban areas) have been eligible for the programme.

Despite its success in rural areas of Mexico in terms of education, health and nutrition -especially for children (Hoddinott and Bassett, 2008) - the literature reveals that the expansion of the programme to urban areas since 2001 has been subject to several constraints. Indeed, the participation rate of eligible households (or take-up rate) has been limited in cities (around 50\%). According to Angelucci, Attanasio and Di Maro (2012) and Behrman and others (2012), there are several reasons for the high level of exclusion errors in urban areas. Firstly, the process of self-selection by participants has led to a number of involuntary exclusions. Among the $40 \%$ of households who were eligible but did not apply for the programme, one third of them reported not being aware of its existence. Therefore, almost 30\% of eligible urban households have voluntarily chosen not to enrol (i.e. self-exclusion). In addition, the annual dropout rate, mainly due to conditionality violations, is more than $7 \%$ in urban areas, compared to $3 \%$ in rural areas. Surprisingly, contrary to the self-targeting theory, the poorest urban households are more likely to drop out of the programme (González-Flores, Heracleous and Winters, 2012). In line with theory on take-up, eligible households appear to make a rational choice between the programme's benefits and its enrolment costs. Therefore, in addition to not being aware of the programme and its eligibility criteria, an imbalance between the cash incentives and the cost of living in cities might explain the programme's low take up and enrolment among the poorest eligible urban households (as well as its ability to retain them); the value of cash transfers are the same in rural and urban areas (Angelucci and Attanasio, 2009), although the cost of living is very different. Therefore, the cash incentives appear to be too low to encourage a substantial portion of eligible urban households to enrol and to offset conditionality-related constraints (direct and indirect costs, preference for immediate gratification, etc.). 
Oddly, there have been no empirical studies of how cash transfers affect take-up and dropout rates. Be that as it may, the value of cash incentives is an adjustable variable that can more than proportionally improve both these rates (Attanasio, Meghir and Schady, 2010).

Using a quantitative design based on panel data from the Mexican Family Life Survey (MxFLS), this study seeks to better understand the determinants of the low take-up rate that characterizes the urban version of the Mexican CCT programme. More specifically, this is the first study to assess the direct influence of cash incentives on dropout risks by considering a large spectrum of take-up determinants. Identification of dropout determinants will be useful for programme administrators, enabling them to minimize exclusion errors. Indeed, exclusion errors are particularly high in cities: three quarters of dropouts from the programme are a result of failing to meet the conditions linked to health- and nutrition-related requirements, and to fulfil other procedural requirements (González-Flores, Heracleous and Winters, 2012).

The rest of the article is structured as follows: the Mexican CCT programme is summarized in section II; the existing literature that analyses the low take-up of the programme in urban areas is outlined in section III; in section IV the data is described and the empirical strategy is established; the results are discussed in section V; lastly, some conclusions are provided in section VI.

\section{The Mexican conditional cash transfer (CCT) programme}

\section{Benefits}

The Mexican programme offers two types of cash transfers: (i) basic aid to increase household food consumption; and (ii) optional grants to encourage school attendance. Each type of transfer is linked to specific conditionalities.

In exchange for basic food aid (the same amount is transferred to all participants), each household member must visit the nearest health centre every two months for medical check-ups. The person receiving the transfers (generally the mother) is also required to attend monthly public health training and preventive health or nutritional meetings (called pláticas, or chats). Every month, health centres report attendance to the programme administrators. Households that have not complied with these conditionalities for four consecutive months (or six non-consecutive months in one year) automatically lose their entitlement to all of the programme's benefits.

As regards the school grants, the transfer amount varies, as it is determined according to the number of school-age children in the household, their school year, and their gender (see table A1.1 in annex A1). The programme sets a maximum transfer threshold (Skoufias, 2005), presumably to avoid possible adverse fertility incentives. To benefit from a full grant, a student must enrol in a school approved by the Secretariat of Public Education (SEP) and attend at least $85 \%$ of classes in a month. Registration and attendance are reported by the school authority to the programme administrators. If school attendance is below $85 \% \mathrm{a}$ proportional amount is deducted from the bimonthly payment. For example, if a student was absent from $50 \%$ of classes over the preceding two months, the household will receive $50 \%$ of the grant.

To conclude, unlike the basic food transfer, grant-related conditionalities do not necessarily lead to definitive exclusions, but rather to payment reductions (Álvarez, Devoto and Winters, 2008). This means that a household can enrol in part of the programme, provided that the health and nutrition component is met. However, if a household does not comply with the health and nutrition component, but continues to send its children to school, it will permanently lose entitlement to all of the programme's benefits. 


\section{The process of selecting beneficiaries}

Under the Mexican CCT programme, the beneficiary targeting strategy includes a dual selection process. First, a geographical selection of the poorest communities was carried out. Since the level of concentration of poor households is very different between rural and urban areas, the geographic selection process is region-specific (Orozco and Hubert, 2005). Eligible households are located in preselected rural communities and urban blocks. In other words, only poor households belonging to poor communities are eligible.

In eligible selected rural communities, face-to-face interviews were conducted at potential beneficiaries' homes. Hence, a quasi-exhaustive census of the inhabitants of rural areas was conducted. Rural households that meet the eligibility criteria were in effect invited to enrol. However, for cost reasons, this process could not be replicated for eligible urban blocks; instead, a self-selection system was established. First, households living in eligible urban blocks were informed about the programme through announcements made from cars with loudspeakers driving around selected neighbourhoods, adverts and radio messages. Households that consider themselves eligible must go to the nearest temporary reception desk (located in health centres), where they are interviewed as part of the National Survey of Urban Households' Socioeconomic Characteristics (ENCASURB). The information is entered directly into a computer system and simultaneously checked against a multivariate poverty index (homogeneous at the national level since 2001) which generates a score (puntaje) (see Skoufias, Davis and De la Vega, 2001). Finally, for households that meet the eligibility criteria (a puntaje above 0.69), home visits are then performed to check the accuracy of the data provided during the interview. The programme administrators then perform a recertification process every three years to limit inclusion errors. During recertification, the puntaje is reassessed with updated household information. Households with a puntaje above 0.383 remain full beneficiaries, households with a puntaje below 0.077 are excluded entirely and households with a puntaje between 0.077 and 0.383 are transferred to a reduced version of the programme (called the Differentiated Support Scheme (EDA)) for an additional three years before being excluded. Households transferred to EDA continue to receive nutritional benefits, the basic health package and grants for secondary school students.

This system of self-selection has resulted in the exclusion of many eligible urban households. Angelucci, Attanasio and Di Maro (2012) estimate that around 50\% of potentially eligible urban households do not benefit from the programme, in contrast to a rate of less than $10 \%$ for rural households. Behrman and others (2012) report that around one third of non-participating eligible urban households were not aware of the programme. In other words, more than two thirds of eligible non-participants freely chose not to enrol despite being able to do so. Although some eligible households were probably unsure whether they were eligible, many voluntarily decided to self-exclude, probably because programme payments are insufficiently attractive with regard to the cost of living in urban areas. It should be borne in mind that the value of cash allowances is identical in rural and urban areas, despite an evident difference in living costs.

\section{Relevant literature}

As discussed in the literature, the dropout rate is much higher in urban areas than in rural areas. While the annual dropout rate is 3\% in rural settings, this rate is more than $7 \%$ in cities. Hence, the total dropout rate between 2002 and 2007 is around 43\% in urban areas, compared to just 16\% in rural settings (Álvarez, Devoto and Winters, 2008). González-Flores, Heracleous and Winters (2012) estimate that three quarters of people drop out because of choices they made, with $56 \%$ doing so 
because they failed to meet the conditions linked to the health- and nutrition-related requirements, and $18 \%$ because they failed to fulfil other procedural requirements. Consequently, only one quarter of programme dropouts are attributable to the three-year recertification process (20\%) and audits (6\%) by the programme administrators to reduce inclusion errors.

According to self-targeting theory, the relationship between socioeconomic status and dropout probability should be positive and linear. Indeed, the constraints related to conditionalities compliance ought to act as a self-regulation mechanism (González-Flores, Heracleous and Winters, 2012). This means that less needy households should self-exclude themselves from the programme, given a relatively high opportunity cost and the existence of better alternatives (owing to better skills, higher migration opportunities, among other factors). However, the empirical findings from González-Flores, Heracleous and Winters (2012) refute the self-targeting hypothesis in the context of Mexican urban areas. Based on administration data, these authors describe a U-shaped relationship between the puntaje (poverty index) and dropout probability. In addition, the most vulnerable participants (such as single-parent families) are the most likely to drop out. This last finding suggests that the direct and indirect costs related to meeting the programme requirements, combined with poor understanding of the scheme and its benefits, have a very negative effect on the long-term participation of the poorest households. González-Flores, Heracleous and Winters (2016) also note that half of urban participants choose to forgo full grants, as they fail to comply with the requirement to send their children to school. This failure to comply with the educational component is particularly prevalent among the poorest households and mainly concerns high school grants. This conclusion highlights the fact that, for adolescents, the opportunity cost of studying rather than working is much higher in cities than in rural areas. According to Schultz (2004), the grants provided through the programme represent between half and one third of a full-time wage in Mexican cities.

González-Flores, Heracleous and Winters (2012) report that dropout probability is positively correlated with city size. They postulate that this may be partly due to the congestion that characterizes large Mexican cities, leading to higher direct (travel prices) and indirect (time spent in transportation) transport costs. Moreover, as living costs theoretically increase in line with city size, the purchasing power offered by cash transfers (which are the same in all areas) probably decreases with city size. In other words, in large cities, cash incentives may not offset the direct and indirect costs related to compliance with conditionalities. Lastly, González-Flores, Heracleous and Winters (2012) observe that dropout probability is negatively correlated with the level of community marginality (percentage of poor households in the community). The authors' suggest that a possible explanation for this is linked to network theory: since the density of participants is low in less marginal communities, poor people in those communities are less likely to obtain information about the programme.

\section{The data and empirical strategy}

The data used in this study are from the Mexican Family Life Survey (MxFLS), the first survey with a representative sample of the Mexican population at the national, rural-urban and regional levels. Its sampling guidelines were drawn up by the National Institute of Statistics and Geography (INEGI). The survey contains information for a 10-year period, collected in three rounds. The first round was carried out in 2002, surveying 35,677 individuals from 8,440 households (living in 150 municipalities across 16 Mexican states). Given the longitudinal design of the survey, the second (2005/06) and third (2009-2012) rounds were based on the initial sample from 2002, with almost $90 \%$ of the original sampled households located and reinterviewed. The Survey includes data on programme take-up and the amount received yearly by participants through cash transfers, as well as detailed information on the socioeconomic and demographic characteristics of households and individuals. 
The main goal of this study is to empirically assess the influence of cash incentives on programme dropout probability in urban areas of Mexico. Consequently, only urban households that were enrolled and received cash transfers in 2005 were examined. Those who continued to participate in the programme were then differentiated from those who dropped out, using treatment status information from the 2012 survey. Since MxFLS is representative at the rural-urban level, the households in the urban sample are assumed to be representative of enrolled households in all urban areas of Mexico. The reduced-form model based on urban participants takes the form of a probit binomial regression:

$$
P\left(\text { Stayer }_{j}\right)=\alpha+\beta_{1} X_{j}+\beta_{2} \text { cash }_{j}+\varepsilon_{j}
$$

Where $P\left(\right.$ Stayer $\left._{j}\right)$ is the probability of a household $j$ remaining a participant between 2005 and 2012, rather than leaving the programme in that periods. $X_{j}$ is a vector of control variables measured in 2005 that includes socioeconomic and demographic characteristics of the head of the household (age, gender, annual labour income, civil status, education and socio-professional status) and of the whole household (number of children by age group, percentage of girls, dependency ratio and owned assets). The vector $X_{j}$ also includes a community factor to capture the size of cities and their level of urban development in 2005 (a composite index measuring the availability of infrastructure assets in the municipality). Finally, $c a s h_{j}$ is the total value of the transfers (in pesos) that the household received in 2005. In theory, the households that received the most cash were those who were enrolled for longer in the programme or who accumulated more school grants (by having older or female school-age children, see table A1.1 in annex A1). For this reason, a control was included for the number of children by age group and the percentage of girls within each enrolled household. The cash transfers variable was analysed using two different approaches: linearly, using a logarithmic transformation of annual cash payments and non-linearly using a quartile categorization of the distribution. Outlier values are excluded according to reasonable thresholds of transfers based on the estimated values in table A1.1 in annex A1. The variables used in the model are described in table A1.2 in annex A1.

The purpose of equation 1 is to test the following hypotheses:

- $\mathrm{H} 1$ (self-targeting hypothesis): For enrolled households, if the relationship between socioeconomic status and the probability of staying in the programme is negative and linear, this means that less needy households self-exclude from the programme, owing to a relatively high opportunity cost and the existence of better alternatives. In this case, the self-targeting hypothesis is accepted and the efficiency of the programme is thus limited by inclusion errors. On the other hand, if there is an inverted- $U$ or positive relationship between socioeconomic status and the probability of staying in the programme, the self-targeting hypothesis is rejected, and the efficiency of the programme is thus limited by exclusion errors.

- $\quad \mathrm{H} 2$ (hypothesis of a lack of cash incentives): If cash transfers are not sufficient to retain the poorest households in the programme -households that are theoretically not concerned by self-targeting and recertification processes - one could assume that cash allowances do not offset the constraints linked to compliance with the programme's conditionalities. To test this hypothesis, an interaction term is included in an alternative specification of equation 1: the value of transfers is cross referenced with the income quartile of the head of the household.

In the interest of clarity and transparency, the robustness of the empirical model with regard to endogeneity problems must be properly discussed. Clearly, the time interval between the regressors and the outcome indicator dismisses the potential presence of reverse causality in the model; whether a participant is a "stayer" or a "leaver" in 2012 does not affect the value of cash payments made in 2005 or his or her socioeconomic status in 2005. However, the omission of factors that are simultaneously 
correlated with the regressors and the unexplained variance of the probability of staying enrolled $\left(\varepsilon_{j}\right)$ could bias the probit estimations (equation 1). For example, household members' concern about education and health and their cognitive skills are assumed to be positively and simultaneously correlated with the household's socioeconomic status (included in $X_{j}$ ), the accumulated value of grants (included in cash payments, $c a s h_{j}$ ) and the degree of programme involvement and understanding (and thus with $P\left(\right.$ Stayer $\left._{j}\right)$ ). Intuitively, such an omission might cause overestimation of the positive relationship between socioeconomic status and the probability of staying in the programme and, thus erroneously, result in rejection of the self-targeting hypothesis $(\mathrm{H} 1)$. Regarding $\mathrm{H} 2$, these omitted factors might also cause overestimation of the positive relationship between cash transfers and the probability of staying in the programme. Unfortunately, these intuitions can only be partially tested, since such factors are often unobserved. However, this study attempts to capture these undesirable biases by including the highest cognitive skills score obtained by the adult household members in an alternative specification of equation $1 .{ }^{1}$ Furthermore, as mentioned earlier, the number of children by age groups is taken into consideration to limit endogeneity biases. The omission of this factor could have resulted in an underestimation of the positive effect of cash incentives on the probability of staying enrolled in the programme $(\mathrm{H} 2)$. Indeed, households with older children potentially received more through grants in 2005 (see table A.1) and thus have a higher dropout probability during a recertification process, owing to the possible coming of age of their children (because the puntaje is calculated using the number of minor children).

Another possible limitation of this study concerns the attrition of panel data between 2005 and 2012. However, there is no reason to assume that many of the households that no longer participated in the survey (for reasons such as migration) would have left the programme if they had continued to be included in the survey. Moreover, the potential programme dropouts who also left the survey are likely to have the same characteristics as the dropouts that remained in the survey. Therefore, we consider that panel attrition is not correlated with the probability of leaving the programme and thus does not affect the results.

\section{Results}

\section{Descriptive statistics}

As expected, the participation rate of households in the programme (based on the total samples) is significantly higher in rural areas than in urban communities (see table 1); while about one quarter of rural households enrolled in the programme in the 2002-2012 period, the participation rate of urban households increased from 3\% in 2002 to $6 \%$ in 2012. This increase is probably related to the gradual expansion of the programme. While the participation rate in large cities (more than 100,000 inhabitants) tripled between 2002 and 2012, this rate only doubled in medium-sized cities (between 15,000 and 100,000 inhabitants) and increased by just 40\% in small towns (between 2,500 and 15,000 inhabitants). In addition, the participation rate decreases as city size increases. In line with González-Flores, Heracleous and Winters (2012), this study concludes that implementation of the programme has proven difficult in major urban centres.

Table 2 shows that dropout rates from the programme are significantly higher in cities than in rural areas. One could conclude that this large gap is because poverty is less prevalent in urban areas than in rural ones. Nonetheless, several elements suggest that it might also be explained by the fact that urban cash incentives do not offset the constraints associated with compliance with conditionalities. Indeed, the cost of living differs significantly between rural and urban areas (see table A1.3 in annex A1).

1 Cognitive skills scores are not included in the main model owing to the low number of observations for this variable. 
Table 1

Household participation rates based on total samples, 2002, 2005/06, 2009-2012

\begin{tabular}{|c|c|c|c|c|c|c|}
\hline & \multicolumn{2}{|c|}{2002} & \multicolumn{2}{|c|}{$2005 / 06$} & \multicolumn{2}{|c|}{ 2009-2012 } \\
\hline & Number & $\begin{array}{c}\text { Treated } \\
\text { (percentages) }\end{array}$ & Number & $\begin{array}{c}\text { Treated } \\
\text { (percentages) }\end{array}$ & Number & $\begin{array}{c}\text { Treated } \\
\text { (percentages) }\end{array}$ \\
\hline Urban areas & 10616 & 3 & 10598 & 4 & 10446 & 6 \\
\hline more than 100000 inhabitants & 6812 & 1 & 6639 & 2 & 6475 & 3 \\
\hline between 15000 and 100000 inhabitants & 1863 & 3 & 1849 & 5 & 1866 & 6 \\
\hline between 2500 and 15000 inhabitants & 1941 & 9 & 2110 & 10 & 2105 & 13 \\
\hline Rural areas & 7834 & 25 & 7969 & 26 & 8304 & 26 \\
\hline \multirow{2}{*}{$\begin{array}{l}\text { Rural vs. urban mean-comparison test } \\
\text { (p-value) }\end{array}$} & & 22 & & 22 & & 20 \\
\hline & & $(0.000)$ & & $(0.000)$ & & $(0.000)$ \\
\hline
\end{tabular}

Source: Prepared by the author, on the basis of Ibero-American University (IBERO)/Center for Economic Research and Teaching (CIDE), "Mexican Family Life Survey" [online] http://www.ennvih-mxfls.org/english/index.html.

Table 2

Household dropout rates, 2005/06 and 2009-2012

\begin{tabular}{|c|c|c|c|c|}
\hline & \multicolumn{2}{|c|}{ Enrolled in 2002} & \multicolumn{2}{|c|}{ Enrolled in 2005/06 } \\
\hline & Number & $\begin{array}{l}\text { Dropout rate in 2005/06 } \\
\text { (Percentages) }\end{array}$ & Number & $\begin{array}{c}\text { Dropout rate in 2009-2012 } \\
\text { (Percentages) }\end{array}$ \\
\hline Urban areas & 269 & 64 & 401 & 55 \\
\hline more than 100000 inhabitants & 49 & 82 & 119 & 64 \\
\hline between 15000 and 100000 inhabitants & 46 & 67 & 83 & 59 \\
\hline between 2500 and 15000 inhabitants & 174 & 57 & 199 & 47 \\
\hline Rural areas & 1769 & 49 & 1858 & 45 \\
\hline \multirow{2}{*}{$\begin{array}{l}\text { Rural vs. urban mean-comparison test } \\
\text { (p-value) }\end{array}$} & & 15 & & 9 \\
\hline & & $(0.000)$ & & $(0.000)$ \\
\hline
\end{tabular}

Source: Prepared by the author, on the basis of Ibero-American University (IBERO)/Center for Economic Research and Teaching (CIDE), "Mexican Family Life Survey" [online] http://www.ennvih-mxfls.org/english/index.html.

In contrast, table 3 shows no significant payments gap between rural and urban areas in 2005. In addition, the distribution of cash transfers is similar in the two areas (see figure A1.1 in annex A1) and head of the household's socioeconomic status does not substantially affect the value of cash incentives (see table A1.4 in annex A1). The lack of correlation between socioeconomic status and cash transfers indicates that the payment amounts are not proportional to the level of poverty, meaning that each beneficiary is entitled to the same amount. It also suggests that there is no significant corruption within the programme; there is no discernible group of richer participants who receive a disproportionately large portion of the cash payments.

Table 3

Annual cash transfers received by households in 2005/06

(Pesos)

\begin{tabular}{lccccc}
\hline & Number & Mean & Quartile I & Median & Quartile III \\
\hline Urban areas & 155 & 3299 & 1500 & 2040 & 4800 \\
\hline Rural areas & 662 & 3286 & 1800 & 2040 & 4200 \\
\hline $\begin{array}{l}\text { Rural vs. urban mean-comparison test } \\
\text { (p-value) }\end{array}$ & \multicolumn{5}{c}{12.23} \\
\cline { 2 - 6 }
\end{tabular}

Source: Prepared by the author, on the basis of Ibero-American University (IBERO)/Center for Economic Research and Teaching (CIDE), "Mexican Family Life Survey" [online] http://www.ennvih-mxfls.org/english/index.html. 


\section{Determinants of programme dropouts}

Since the main objective of this study is to evaluate the impact of cash payments on the probability of participants staying in or dropping out of the Prospera programme, only households that were enrolled in the programme during the 2005/06 survey are analysed. As the next step, "stayers" and "leavers" were then identified using treatment status information from the 2012 survey. A probit regression was used to estimate the relationship between annual cash transfers received a year before the 2005/06 survey and the probability of staying in the programme rather than leaving between 2005/06 and 2009-2012 (see table 4). A control for the presence of heterogeneity between "stayers" and "leavers" was applied, using a comprehensive set of control variables collected during the 2005/06 survey. As discussed earlier, these control variables partially address the assumed endogeneity problems. These covariates include characteristics at the head of household level, at the household level and at the municipality level. Standard errors are clustered at the municipality level to correct for potential intracommunity correlation, such as specific enrolment facilities. The number of observations is relatively small owing to the low participation rate in Mexican cities. Hence, there are 98 enrolled households in the urban sample. However, the probit estimates are of suitable quality: the pseudo-R2s are high (between $45 \%$ and $58 \%)^{2}$ Despite a small number of observations, the standard errors are not high and various explanatory variables are significant. This last point is not surprising, since all enrolled households have relatively homogeneous characteristics; both "stayers" and "leavers" are poor households.

Table 4

Determinants of the probability of staying compared to those of leaving in urban areas, average marginal effects

\begin{tabular}{|c|c|c|c|c|c|}
\hline \multirow{2}{*}{ Dependent variable } & \multicolumn{5}{|c|}{ Staying versus leaving the programme between 2005 and 2012} \\
\hline & $(1)$ & $(2)$ & (3) & (4) & $(5)$ \\
\hline \multirow[t]{2}{*}{ Age of the head of the household $(\mathrm{HH})$} & $0.0385^{\star \star \star}$ & $0.0352^{\star * \star}$ & $0.111^{\star \star \star}$ & $0.0430^{* \star \star}$ & $0.0468^{\star \star \star}$ \\
\hline & $(2.980)$ & $(3.011)$ & $(3.481)$ & $(5.416)$ & $(4.520)$ \\
\hline \multirow[t]{2}{*}{ Sex of HH (male) } & $-0.692^{* * *}$ & $-0.713^{\star * *}$ & $-0.955^{\star \star *}$ & $-0.515^{\star}$ & $-0.689^{\star \star *}$ \\
\hline & $(-3.396)$ & $(-3.725)$ & $(-3.333)$ & $(-1.804)$ & $(-4.078)$ \\
\hline \multirow[t]{2}{*}{ Civil status of HH (in a couple) } & $0.625^{\star \star \star}$ & $0.597^{\star \star \star}$ & $0.797^{\star \star \star}$ & $0.582^{\star \star \star}$ & $0.621^{\star \star \star}$ \\
\hline & $(3.880)$ & $(4.096)$ & $(3.246)$ & $(3.415)$ & $(3.945)$ \\
\hline \multirow[t]{2}{*}{ Number of young children ( $0-5$ years old) } & $0.161^{*}$ & $0.171^{*}$ & $0.469^{\star \star \star}$ & 0.0486 & $0.146^{*}$ \\
\hline & $(1.872)$ & $(1.946)$ & (2.834) & $(0.527)$ & (1.768) \\
\hline \multirow{2}{*}{ Number of older children (6-12 years old) } & $0.260^{\star \star \star}$ & $0.260^{* *}$ & $0.501^{\star * *}$ & $0.226^{\star \star}$ & $0.372^{\star \star \star}$ \\
\hline & $(2.718)$ & $(2.490)$ & (3.529) & $(2.406)$ & $(2.913)$ \\
\hline \multirow[t]{2}{*}{ Number of adolescents (13-15 years old) } & -0.0152 & 0.0150 & 0.0357 & -0.0365 & -0.0684 \\
\hline & $(-0.146)$ & $(0.132)$ & $(0.253)$ & $(-0.376)$ & $(-0.522)$ \\
\hline \multirow[t]{2}{*}{ Percentage of girls ( $0-15$ years old) } & -0.00126 & -0.00117 & -0.000330 & 0.000760 & -0.00119 \\
\hline & $(-0.629)$ & $(-0.553)$ & $(-0.116)$ & $(0.348)$ & $(-0.494)$ \\
\hline \multirow[t]{2}{*}{ Age-dependency ratio } & -0.138 & -0.140 & $-0.791^{\star \star \star}$ & -0.0168 & -0.0573 \\
\hline & $(-1.461)$ & $(-1.099)$ & $(-3.005)$ & $(-0.137)$ & $(-0.465)$ \\
\hline \multirow[t]{2}{*}{ HH has no education } & 0.132 & 0.125 & -0.180 & 0.0340 & 0.275 \\
\hline & $(0.787)$ & $(0.809)$ & $(-0.768)$ & $(0.216)$ & (1.507) \\
\hline \multirow{2}{*}{$\begin{array}{l}\text { Highest cognitive skills score obtained } \\
\text { by adult household members }\end{array}$} & & & $-0.00891^{*}$ & & \\
\hline & & & $(-1.742)$ & & \\
\hline \multirow[t]{2}{*}{ Informal salaried worker $(\mathrm{HH})^{\mathrm{a}}$} & $0.401^{\star \star}$ & $0.398^{* \star}$ & $0.592^{\star \star}$ & $0.388^{*}$ & $0.654^{\star \star \star}$ \\
\hline & $(2.512)$ & (2.448) & (2.391) & $(1.713)$ & (3.290) \\
\hline
\end{tabular}

2 By running linear regressions of equation 1 (based on a linear least squares estimator), we observe that the R2s have similar values to the pseudo-R2s (not shown). This means that the variance of the selected regressors explains around $45 \%-60 \%$ of the variance in the probability of staying in the programme. The highest R2s and pseudo-R2s are found in the specification that includes the highest cognitive skills scores obtained by adult household members (see column 3 of table 4). 
Table 4 (concuded)

\begin{tabular}{|c|c|c|c|c|c|}
\hline \multirow{2}{*}{ Dependent variable } & \multicolumn{5}{|c|}{ Staying versus leaving the programme between 2005 and 2012} \\
\hline & (1) & (2) & (3) & (4) & $(5)$ \\
\hline \multirow[t]{2}{*}{ Formal salaried worker $(\mathrm{HH})^{\mathrm{a}}$} & $0.472^{*}$ & $0.507^{*}$ & $0.749^{\star \star \star}$ & $0.565^{\star *}$ & $0.589^{\star *}$ \\
\hline & $(1.777)$ & $(1.838)$ & (3.329) & $(2.032)$ & $(2.324)$ \\
\hline \multirow[t]{2}{*}{ Self-employed worker $(\mathrm{HH})^{\mathrm{a}}$} & $0.503^{\star \star \star}$ & $0.545^{\star \star \star}$ & $0.763^{\star \star \star}$ & $0.577^{\star \star \star}$ & $0.756^{\star \star \star}$ \\
\hline & $(3.940)$ & $(4.078)$ & (3.199) & $(3.080)$ & $(4.303)$ \\
\hline \multirow[t]{2}{*}{ Labour income of HH-quartile I } & & & & & $1.000^{\star \star *}$ \\
\hline & & & & & $(3.247)$ \\
\hline \multirow[t]{2}{*}{ Labour income of $\mathrm{HH}$-quartile ॥ } & $0.691^{\star *}$ & $0.673^{\star \star}$ & $0.980^{\star \star \star}$ & $-1.000^{\star \star \star}$ & \\
\hline & $(2.482)$ & $(2.117)$ & (3.192) & $(-2.582)$ & \\
\hline \multirow[t]{2}{*}{ Labour income of HH-quartile III } & 0.457 & 0.394 & $0.902^{\star \star \star}$ & $-0.989^{\star \star}$ & \\
\hline & $(1.633)$ & $(1.274)$ & (2.814) & $(-2.534)$ & \\
\hline \multirow[t]{2}{*}{ Labour income of HH-quartile IV } & $0.521^{*}$ & 0.465 & $0.948^{\star \star \star}$ & $-0.997^{\star \star}$ & \\
\hline & $(1.708)$ & $(1.362)$ & (3.094) & $(-2.252)$ & \\
\hline \multirow[t]{2}{*}{ Owned assets index } & $-1.017^{\star \star \star}$ & $-1.020^{\star \star \star}$ & $-1.319^{\star \star \star}$ & $-0.859^{\star \star \star}$ & $-1.501^{\star \star \star}$ \\
\hline & $(-3.229)$ & $(-3.112)$ & $(-3.406)$ & $(-3.478)$ & $(-3.456)$ \\
\hline \multirow[t]{2}{*}{ Square of owned assets index } & $0.159^{\star \star \star}$ & $0.157^{\star \star \star}$ & $0.197^{\star \star \star}$ & $0.141^{\star \star \star}$ & $0.222^{\star \star \star}$ \\
\hline & (3.689) & $(3.554)$ & (3.478) & (3.799) & (3.475) \\
\hline \multirow[t]{2}{*}{ Infrastructure development index } & $-0.210^{\star \star \star}$ & $-0.221^{* \star *}$ & $-0.295^{\star \star}$ & $-0.164^{* *}$ & $-0.188^{\star \star}$ \\
\hline & $(-3.374)$ & $(-3.665)$ & $(-2.303)$ & $(-2.418)$ & $(-2.144)$ \\
\hline \multirow[t]{2}{*}{ log(transfers) } & $0.228^{\star \star \star}$ & & & $-0.479^{\star \star \star}$ & $0.513^{\star \star \star}$ \\
\hline & (3.049) & & & $(-2.711)$ & $(3.276)$ \\
\hline \multirow[t]{2}{*}{ Transfers-quartile II (1 500-2 040 pesos/year) } & & 0.247 & $0.722^{\star \star}$ & & \\
\hline & & $(1.157)$ & (2.136) & & \\
\hline \multirow[t]{2}{*}{ Transfers-quartile III (2 040-4 800 pesos/year) } & & 0.127 & 0.256 & & \\
\hline & & $(0.633)$ & $(1.097)$ & & \\
\hline \multirow[t]{2}{*}{ Transfers-quartile IV (>4 800 pesos/year) } & & $0.548^{* \star *}$ & $0.799^{\star \star \star *}$ & & \\
\hline & & (3.905) & $(4.955)$ & & \\
\hline \multirow[t]{2}{*}{ log(transfers)*Income quartile I } & & & & & $-1.107^{\star \star \star}$ \\
\hline & & & & & $(-3.660)$ \\
\hline \multirow[t]{2}{*}{$\log ($ transfers)*Income quartile II } & & & & $0.856^{\star \star \star}$ & \\
\hline & & & & $(2.937)$ & \\
\hline \multirow[t]{2}{*}{$\log ($ transfers)*Income quartile III } & & & & $0.748^{\star \star \star}$ & \\
\hline & & & & $(2.906)$ & \\
\hline \multirow[t]{2}{*}{$\log ($ transfers)*Income quartile IV } & & & & $0.639^{\star \star}$ & \\
\hline & & & & $(2.519)$ & \\
\hline Observations & 98 & 98 & 89 & 98 & 98 \\
\hline Pseudo- $\mathrm{R}^{2}$ & 44.84 & 46.91 & 58.37 & 47.70 & 54.42 \\
\hline
\end{tabular}

Source: Prepared by the author, on the basis of Ibero-American University (IBERO)/Center for Economic Research and Teaching (CIDE), "Mexican Family Life Survey" [online] http://www.ennvih-mxfls.org/english/index.html.

Note: Cluster robust z-statistics (at the municipality level) are in brackets: ${ }^{\star \star \star} p<0.01,{ }^{\star \star} p<0.05,{ }^{*} p<0.1$.

a The reference group comprises inactive, unemployed and unpaid heads of household.

Columns 1 and 2 of table 4 present the results of equation 1. The marginal effects of control variables are consistent with the results from González-Flores, Heracleous and Winters (2012). For instance, the greater the development of infrastructure in an urban municipality, the higher the dropout probability tends to be. It is likely that participants' concentration in the most marginalized communities leads to better dissemination and understanding of the programme. Moreover, as expected, having several young and preadolescent children in the household significantly increases the probability of staying enrolled between 2005/06 and 2009-2012. Interestingly, the percentage of girls has no impact on the probability of staying in the programme. One could have expected households with several girls receiving school grants to be more interested in staying enrolled, as the grants for girls are larger than those for boys (see table A1.1 in annex A1). In terms of the characteristics of heads of households, our 
results support the findings of González-Flores, Heracleous and Winters (2012): when the head of the household is a woman, has a partner and is older, the probability of staying in the programme significantly increases. In contrast, heads of households who belong to a low occupational category (inactive, unemployed or unpaid) are at greater risk of dropping out. With regard to the head of the household's labour income, the richest $75 \%$ are more likely to stay in the programme than the poorest $25 \%$. The probability of staying is particularly high for quartile II, compared to quartile I (67 to 69 percentage points higher). This non-linearity is extensively discussed by González-Flores, Heracleous and Winters (2012) who observe a U-shaped relationship between the poverty index (the puntaje) and dropout risk in urban areas. In short, in accordance with the seminal work of González-Flores, Heracleous and Winters (2012), our results highlight the difficulties in raising awareness of the programme among the most vulnerable participants (such as the inactive, unemployed and poor.) and encouraging them to enrol and remain in the programme. ${ }^{3}$ Since the poorest participants show a particularly high dropout probability, we can reject the self-targeting hypothesis ( $\mathrm{H} 1$ rejected).

In column 1 of table 4, the annual cash transfers variable is expressed in a linear and logarithmic form. We find that the value of payments increases the probability of staying in the programme (significant at $1 \%)$. An extra unit of the logarithm of transfers raises the probability of staying in the programme by 23 percentage points. In column 2 of table 4, when the value of transfers is expressed in quartile categories, we note that households in quartile IV, which received more than 4,800 pesos in 2005, are more likely to stay in the programme than households in quartile I, which received less than 1,500 pesos. The gap between quartiles I and IV is around 55 percentage points (significant at 1\%). However, there is no significant difference between the first three quartiles of cash transfers (quartiles I, II and III).

Column 3 of table 4 shows an alternative model specification that takes into account the highest cognitive skills score obtained by adult household members. Contrary to our expectations (see section IV), this factor reduces the probability of staying in the programme, although the fitted coefficient is only significant at $10 \%$. It could be speculated that households comprised of adults with high cognitive skills are more likely to leave the programme because they better assess the imbalance between cash payments and conditionality-related costs. Moreover, this endowment of cognitive skills potentially increases the probability of finding more economically attractive opportunities than social cash transfers (e.g. employment opportunities), which is somewhat consistent with the self-targeting theory (see section II.2). So, somewhat counterintuitively, when cognitive skills are omitted from the equation (results in columns 1 and 2), the positive effects of the cash payments and head of household labour income on the probability of staying in the programme are underestimated. Indeed, cognitive skills are assumed to be positively correlated with cash payments and income but negatively correlated with programme participation. As explained in section IV, additional factors, such as level of concern about health and education, could remain unobserved, leading to bias in the results through overestimation of the positive effects of head of household income on the probability of staying in the programme. However, given the high significance and magnitude of the estimated coefficients in table 4, it is assumed that such omitted factors do not significantly bias the estimates.

Lastly, columns 4 and 5 of table 4 present alternative specifications that introduce interaction terms between head of household labour income and the level of the logarithm of transfers. A priori, the head of the household's labour income significantly affects the relationship between cash incentives and the probability of staying in the programme. More specifically, column 4 shows that cash transfers significantly increase the likelihood of staying in the programme for the households in the top three income quartiles (quartiles II, III and IV), compared to the poorest (quartile I). Similarly, column 5 indicates that

3 However, table 4 shows that households with the fewest assets and those with the most are more likely to stay compared to households with an intermediate number of assets. This $U$-shaped relationship between owned assets and the probability of staying is not consistent with our assumptions. Nevertheless, in terms of proportion, very few households are at the left-hand end of the assets distribution: only $7 \%$ of households own between 0 and 2 assets (results available on request). Therefore, this $\mathrm{U}$-shaped relationship might be caused by the presence of extreme cases. 
a one unit increase in log-transfers decreases by 0.6 percentage points ${ }^{4}$ the probability of the poorest $25 \%$ staying compared to the richest $75 \%$ (coefficient significant at 1\%). These results are our most significant contribution to existing literature. In short, the poorest households are particularly sensitive to the low payment amounts that characterize the urban version of the programme. We speculate that the urban cash transfers fail to offset the constraints associated with compliance with conditionalities (such as direct and indirect costs, loss of time and preference for immediate gratification), resulting in the poorest households leaving the programme (H2 accepted).

\section{Conclusions}

In keeping with the seminal work of González-Flores, Heracleous and Winters (2012), we find a positive relationship between head of household income and the probability of staying in the programme for urban Mexican households. This positive trend disproves the self-targeting theory and is indicative of considerable exclusion errors. This finding is critical for the programme's administrators as it calls into question the effectiveness of the scheme in its current format: despite its goals, the programme fails to target and retain the poorest households living in urban areas.

This study contributes to the existing literature by drawing attention, through empirical analysis, to the role of cash incentives as a key determinant of the worryingly high number of programme dropouts in urban areas. In line with theory on take-up, our results highlight the imbalance between cash incentives and conditionality-related constraints that significantly increase exclusion errors and programme dropouts in urban areas of Mexico. Below a certain threshold, cash allowances may not offset the constraints related to compliance with conditionalities (such as direct and indirect costs) and may, therefore, increase the risk of dropping out of the programme. Moreover, the low cash incentives available to households in Mexican cities particularly affect the capacity of the poorest to stay in the programme. This indicates that the conditionalities are particularly difficult to meet for the poorest and most disadvantaged households (as assumed by González-Flores, Heracleous and Winters (2012)). In addition to the apparent inability of the programme to retain the poorest participants, the insufficient cash incentives may dissuade many poor households from even enrolling. Therefore, we can conclude that the relatively low value of the cash transfers in urban areas may largely explain the low participation rate and the high dropout rate.

The results suggest that the cash incentives in Mexican cities are too low (the amount is the same as that paid to rural households) to offset the different constraints arising from compliance with the related conditionalities. Since the cost of living is higher in cities than in rural areas of Mexico, we recommend adapting the value of cash transfers to the urban cost of living. Increasing the value of transfers in urban areas might not only encourage more eligible households to enrol but may also curb the number of dropouts among the poorest beneficiaries. In addition, reducing the number of dropouts and exclusion errors is in the public interest for reasons other than combating poverty. For example, a recent study has shown that long-term enrolment in the programme has a protective effect against weight gain (obesity being a huge problem in emerging countries such as Mexico), while short-term enrolment increases the risk of weight gain (Levasseur, 2019). Evidently, additional analysis is needed to determine the appropriate value of cash transfers for urban households. To minimize the negative externalities that an extra cash payment could generate, such as migration flows or inclusion errors, the programme administrators should take several precautions. For instance, the value of cash payments should be proportional to the cost of living in the municipality and proportional to the poverty level of

$4 \frac{\Delta \text { Prob(staying) }}{\Delta \log \text { (transfers) }}=0.5113+(-1.107) * \Delta$ IncomeQ $1=0.5113+(-1.107) * 1=-0.5957$. 
the eligible household. In addition to potentially discouraging migration, such proportional payments may reduce the risk of dropping out for the poorest households living in the most expensive areas. Lastly, an important finding that should be taken into account is that dropout risk increases in tandem with household vulnerability and city size.

\section{Bibliography}

Álvarez, C., F. Devoto and P. Winters (2008), "Why do beneficiaries leave the safety net in Mexico? A study of the effects of conditionality on dropouts", World Development, vol. 36, No. 4, Amsterdam, Elsevier.

Angelucci, M. and O. Attanasio (2009), "Oportunidades: program effect on consumption, low participation, and methodological issues", Economic Development and Cultural Change, vol. 57, No. 3, Chicago, The University of Chicago Press.

Angelucci, M., O. Attanasio and V. Di Maro (2012), "The impact of Oportunidades on consumption, savings and transfers", Fiscal Studies, vol. 33, No. 3, Oxford, Blackwell Publishing.

Attanasio, O., C. Meghir and N. Schady (2010), "Mexico's conditional cash transfer programme", The Lancet, vol. 375, No. 9719, Amsterdam, Elsevier, 20 March.

Banerjee A. and E. Duflo (2011), Poor Economics: A Radical Rethinking of the Way to Fight Global Poverty, New York, Public Affairs.

Behrman, J. R. and others (2012), "Are conditional cash transfers effective in urban areas? Evidence from Mexico", Education Economics, vol. 20, No. 3, London, Routledge, Taylor \& Francis.

Fiszbein, A. and others (2009), "Conditional cash transfers: reducing present and future poverty", A World Bank Policy Research Report, 47603, Washington, D.C., The World Bank.

González-Flores, M., M. Heracleous and P. Winters (2016), "Conditional cash transfers and schooling decisions: evidence from urban Mexico", IDB Working Paper Series, No. 721, Washington, D.C., Inter-American Development Bank (IADB).

(2012), "Leaving the safety net: an analysis of dropouts in an urban conditional cash transfer program", World Development, vol. 40, No. 12, Amsterdam, Elsevier.

Hernández, D., J. Gómez de León and G. Vásquez (1999), Más oportunidades para las familias pobres: evaluación de resultados del Programa de Educación, Salud y Alimentación: primeros avances, Mexico City, Secretariat of Social Development (SEDESOL).

Hoddinott, J. and L. Bassett (2008), "Conditional cash transfer programs and nutrition in Latin America: assessment of impacts and strategies for improvement", SSRN Scholarly Paper, No. 1305326, Rochester, Social Science Research Network [online] https://papers.ssrn.com/sol3/papers.cfm?abstract_id=1305326.

Levasseur, P. (2019), "Can social programs break the vicious cycle between poverty and obesity? Evidence from urban Mexico", World Development, vol. 113, Amsterdam, Elsevier.

Orozco, M. and C. Hubert (2005), "La focalización en el Programa de Desarrollo Humano Oportunidades de México", Serie de Documentos de Discusión sobre la Protección Social, 32761, No. 0531, Washington, D.C., World Bank.

Schultz, T. P. (2004), "School subsidies for the poor: evaluating the Mexican Progresa poverty program", Journal of Development Economics, vol. 74, No. 1, Amsterdam, Elsevier.

Skoufias, E. (2005), "PROGRESA and its impacts on the welfare of rural households in Mexico", Research Report, 139, Washington, D.C., International Food Policy Research Institute (IFPRI).

Skoufias, E., B. Davis and S. de la Vega (2001), "Targeting the poor in Mexico: an evaluation of the selection of households into PROGRESA", World Development, vol. 29, No. 10, Amsterdam, Elsevier. 


\section{Annex A1}

Table A1.1

Estimates of school grants and basic food transfers under the Mexican CCT programme between 1999 and 2012

(Pesos)

\begin{tabular}{|c|c|c|c|c|c|}
\hline & Dec 1999 & Dec 2002 & Dec 2005 & Dec 2009 & Dec 2012 \\
\hline Basic food transfers per household & 125 & 150 & 170 & 202 & 227 \\
\hline \multicolumn{6}{|l|}{ School grants per child } \\
\hline Third year of primary school & 80 & 96 & 109 & 130 & 145 \\
\hline Fourth year of primary school & 95 & 114 & 129 & 154 & 173 \\
\hline Fifth year of primary school & 125 & 150 & 170 & 202 & 227 \\
\hline Sixth year of primary school & 165 & 198 & 224 & 267 & 300 \\
\hline First year of secondary school for boys & 240 & 289 & 326 & 389 & 436 \\
\hline Second year of secondary school for boys & 250 & 301 & 340 & 405 & 454 \\
\hline Third year of secondary school for boys & 265 & 319 & 360 & 429 & 482 \\
\hline First year of secondary school for girls & 250 & 301 & 340 & 405 & 454 \\
\hline Second year of secondary school for girls & 280 & 337 & 381 & 453 & 509 \\
\hline Third year of secondary school for girls & 305 & 367 & 414 & 494 & 554 \\
\hline \multicolumn{6}{|l|}{ Grant for school materials per children } \\
\hline Primary school & 165 & 198 & 224 & 267 & 300 \\
\hline Secondary school & 205 & 246 & 279 & 332 & 373 \\
\hline Cash transfer ceiling per household & 750 & 902 & 1019 & 1214 & 1363 \\
\hline Inflation multiplier & 1 & 1.2024 & 1.359 & 1.6188 & 1.8172 \\
\hline
\end{tabular}

Source: Prepared by the author, on the basis of D. Hernández, J. Gómez de León and G. Vásquez, Más oportunidades para las familias pobres: evaluación de resultados del Programa de Educación, Salud y Alimentación: primeros avances, Mexico City, Secretariat of Social Development (SEDESOL), 1999, and Ibero-American University (IBERO)/Center for Economic Research and Teaching (CIDE), "Mexican Family Life Survey" [online] http://www.ennvih-mxfls.org/english/index.html.

Note: The inflation multiplier is calculated using the consumer price index provided by the National Institute of Statistics and Geography (INEGI). 
Table A1.2

Descriptions of variables

\begin{tabular}{|c|c|}
\hline Variable & Description \\
\hline Age of the head of the household & Age of the head of household in years. \\
\hline Sex of the head of the household & Male $=1 ;$ Female $=0$ \\
\hline Civil status of the head of the household & In a couple $=1$; Not in a couple $=0$. \\
\hline $\begin{array}{l}\text { Number of children in the } \\
\text { household by age groups }\end{array}$ & $\begin{array}{l}\text { Three age groups were used: } 0-5 \text { years (not in school); } 6-12 \text { years (primary school); } \\
13-15 \text { years. (secondary school) }\end{array}$ \\
\hline Percentage of girls & $\begin{array}{l}\text { The number of girls (aged } 15 \text { or under) is divided by the total number of young household } \\
\text { members aged } 15 \text { or under and the result is multiplied by } 100 \text {. }\end{array}$ \\
\hline Education of the head of the household & No education $=1$; Primary education (at least) $=0$ \\
\hline $\begin{array}{l}\text { Highest cognitive skills score obtained } \\
\text { by household adult members }\end{array}$ & $\begin{array}{l}\text { The cognitive skills score is measured using MxFLS and a standard approach based } \\
\text { on Raven's Progressive Matrices. The score ranges from } 0 \text { (for low cognitive skills) } \\
\text { to } 100 \text { (for high cognitive skills). This study uses the highest score obtained by adult members } \\
\text { within the household because no information was available for each household member. }\end{array}$ \\
\hline Occupational status & $\begin{array}{l}\text { Four categories: inactive, unemployed or unpaid worker (the reference group); informal salaried; } \\
\text { formal salaried; self-employed. }\end{array}$ \\
\hline Labour income of the head of the household & $\begin{array}{l}\text { Annual labour income of heads of the household in pesos were grouped by quartile for analysis. } \\
\text { Labour incomes were corrected for price variations between the Mexican regions using data } \\
\text { from the National Institute of Statistics and Geography (INEGI). }\end{array}$ \\
\hline Owned assets index & $\begin{array}{l}\text { The composite index of household assets adds six dummy variables: a property; a second } \\
\text { property; a motorized vehicle; an electronic device; a household appliance; and an electrical } \\
\text { cooking appliance. Hence, this index ranges from } 0 \text { for the poorest households } \\
\text { to } 6 \text { for the wealthiest. }\end{array}$ \\
\hline Infrastructure development index & $\begin{array}{l}\text { The composite index of infrastructure development of the municipality adds the five following } \\
\text { dummy variables: public transportation; health centre; refuse collection; sewage system; } \\
\text { and running water. Hence, this index ranges from } 0 \text { for the poorest municipalities } \\
\text { to } 5 \text { for the most developed municipalities. }\end{array}$ \\
\hline Age-dependency ratio & $\begin{array}{l}\text { Number of minors (aged under } 18 \text { ) and older persons (aged over } 65 \text { ) in the household, divided } \\
\text { by the number of household members of working age ( } 18 \text { to } 65 \text { years). }\end{array}$ \\
\hline $\begin{array}{l}\text { The annual amount of cash transfers } \\
\text { received by the household }\end{array}$ & $\begin{array}{l}\text { Sum of annual payments received by all household members (in pesos). This variable is } \\
\text { analysed using two approaches: a logarithmic transformation (linear approach) and a quartile } \\
\text { transformation (non-linear or categorical approach) }\end{array}$ \\
\hline
\end{tabular}

Source: Prepared by the author.

Table A1.3

Prices of tortillas and beverages in 2012 by area of residence (Pesos)

\begin{tabular}{lcc}
\hline & Mean price of one kilo of tortillas & Mean price of one bottle of a soft drink \\
\hline Urban areas & 45 & 22 \\
\hline more than 100000 inhabitants & 44 & 23 \\
\hline between 15000 and 100 000 inhabitants & 45 & 21 \\
\hline between 2 500 and 15 000 inhabitants & 46 & 19 \\
\hline Rural areas & 36 & 17 \\
\hline Rural vs. urban mean-comparison test & 8 & 5 \\
\hline (p-value) & $(0.000)$ & $(0.000)$ \\
\hline
\end{tabular}

Source: Prepared by the author, on the basis of Ibero-American University (IBERO)/Center for Economic Research and Teaching (CIDE), "Mexican Family Life Survey" [online] http://www.ennvih-mxfls.org/english/index.html. 
Figure A1.1

Distribution of cash payments by households' area of residence

(Percentage of households and pesos)

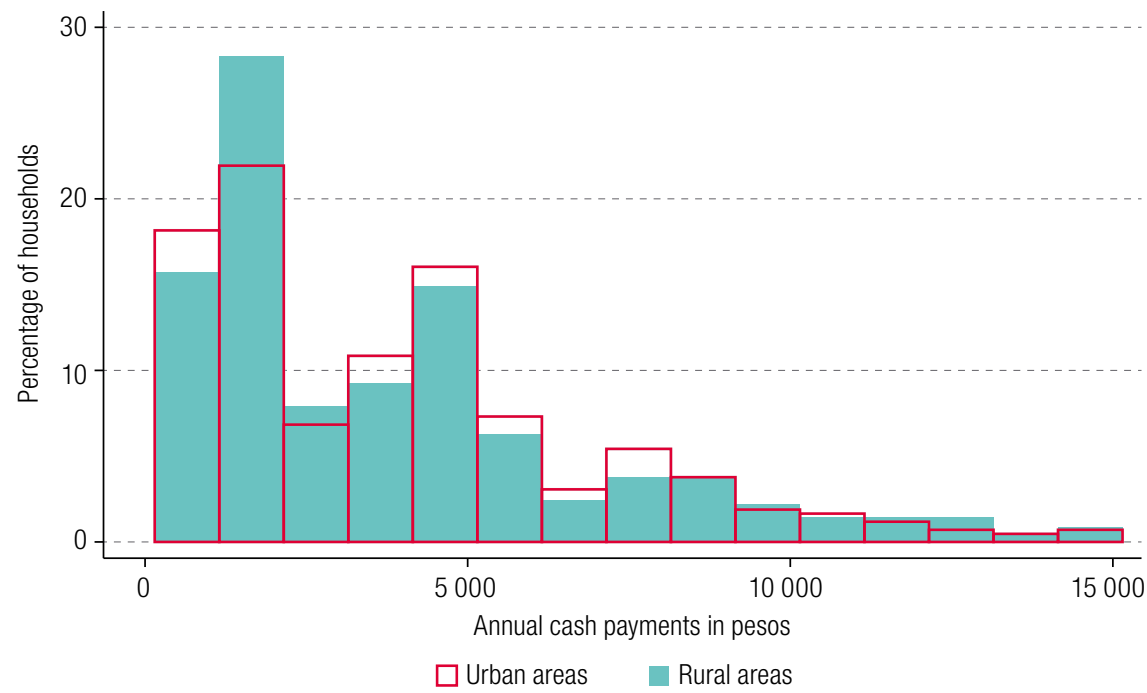

Source: Prepared by the author, on the basis of Ibero-American University (IBERO)/Center for Economic Research and Teaching (CIDE), "Mexican Family Life Survey" [online] http://www.ennvih-mxfls.org/english/index.html.

Table A1.4

Influence of socioeconomic status on the value of cash payments received by participating households, 2005

(Pesos)

\begin{tabular}{lcccc}
\hline & Number & Mean & Standard deviation & Median \\
\hline Labour income of the head of the household (quartile) & & & & \\
\hline Quartile I & 32 & 2691 & 2190 & 2040 \\
\hline Quartile II & 40 & 3066 & 2161 & 2040 \\
\hline Quartile III & 25 & 3182 & 2343 & 2040 \\
\hline Quartile IV & 32 & 3381 & 2645 & 2460 \\
\hline Education of the head of the household & 37 & 3584 & 2771 & 2750 \\
\hline Primary education (minimum) & 115 & 2993 & 2250 & 2040 \\
\hline No education & & & 1897 & 2040 \\
\hline Occupation of the head of the household & 24 & 2373 & 2424 & 2040 \\
\hline Inactive & 64 & 3172 & 2430 & 2040 \\
\hline Informal salaried & 47 & 3163 & 2320 & 3600 \\
\hline Self-employed & 14 & 3640 & & \\
\hline Formal salaried & & & & \\
\hline Source:Prepar
\end{tabular}

Source: Prepared by the author, on the basis of Ibero-American University (IBERO)/Center for Economic Research and Teaching (CIDE), "Mexican Family Life Survey" [online] http://www.ennvih-mxfls.org/english/index.html.

Note: All mean-comparison tests between each group are non-significant at the $10 \%$ level. Thus, we accept the null hypothesis of mean equality between several subsamples. 